\title{
Crítica científica de "Legitimação não tradicional da ação penal": Defensoria Pública e a tutela de direitos por meio do direito penal - uma recusa
}

Scientific criticism of "non traditional legitimation for criminal action": public defender's office and the custody of rights by means of criminal law - one refuse

\section{Patrick Cacicedo}

Doutorando e mestre em Direito Penal e Criminologia pela USP. Defensor Público do Estado de São Paulo. patrickcacicedo@gmail.com http://lattes.cnpq.br/6868425451997606

Dhtt://orcid.org/0000-0002-5623-8224

\section{INTRODUÇÃO}

Em "Legitimação não tradicional da ação penal - a tutela de bens jurídicos por outras instituições públicas", Franklyn Roger Alves Silva examina a questão da legitimidade da ação penal no caso de crimes com sujeito passivo indeterminado e propõe o reconhecimento de uma legitimação supletiva de outras instituições públicas para a promoção da ação penal de tais delitos quando houver inércia do Ministério Público. Trata-se, pois, de estudo sobre a ação penal pública incondicionada em relação aos crimes com bens jurídicos coletivos, cuja "legitimidade da ação penal se restringe ao Ministério Público, não havendo uma válvula de escape apta a persecução destas infrações no caso de inércia de atuação do órgão ministerial.”

Conforme a posição sustentada no artigo, em tais crimes deve haver uma legitimação subsidiária da Defensoria Pública e de outras pessoas jurídicas de direito público, tal qual ocorre nos crimes de ação penal pública in-

1 SILVA, Franklyn Roger Alves. Legitimação não tradicional da ação penal, p. 371. 
condicionada com sujeito passivo determinado, caso no qual a inércia do Ministério Público dá azo à chamada ação penal de iniciativa privada subsidiária da pública, prevista no art. 5 LIX, da Constituição da República. Conforme expressa o autor, "a ação penal de iniciativa privada subsidiária foi construída a partir da legitimação de um ofendido determinado, o que afastaria a sua aplicabilidade da coletividade e de entes despersonalizados"2, de modo que propõe uma "reinterpretação do papel da Defensoria Pública e da Fazenda Pública na defesa da coletividade.”3

Assim, o artigo sustenta a tese de que a Defensoria Pública deve exercer a iniciativa da ação penal pública em matéria de direitos transindividuais em caso de inércia do Ministério Público. Para tanto, parte de uma premissa fundamental que permeia todo o estudo: a de que o direito penal é mecanismo apto a efetivar a tutela de bens jurídicos. A ideia central do texto, polêmica por si, edifica-se em fundamentos igualmente controversos, tais como a existência de uma teoria geral do processo, bem como de efetivação dos direitos humanos por meio da intervenção penal. Com efeito, a despeito da coerência lógica e da qualidade científica do trabalho, a tese sustentada parte de pressupostos teóricos frágeis e acarreta consequências problemáticas ao sistema penal de um modo amplo, o que fragiliza a possibilidade de seu aceite na dogmática processual penal.

\section{1 - A TEORIA DO BEM JURÍDICO ENTRE FUNDAMENTAÇÃO E LIMITAÇÃO DO PODER PUNITIVO}

Desde Birnbaum ${ }^{4}$, a teoria do bem jurídico passou por grande desenvolvimento na história da teoria do delito ${ }^{5}$, havendo atualmente intensa produção científica sobre o tema. Embora não seja a temática

2 SILVA, Franklyn Roger Alves. Legitimação não tradicional da ação penal, p. 385.

3 SILVA, Franklyn Roger Alves. Legitimação não tradicional da ação penal, p. 386.

4 BIRNBAUM, Johann Michael Franz. Sobre la necesidad de una lesión de derechos para el concepto de delito. Traducción de José Luiz Guzmán Dalbora. Buenos Aires: B de F Editorial, 2010.

5 Sobre a evolução histórica da teoria do bem jurídico, Cf. BECHARA, Ana Elisa Liberatore Silva. Teoria do Bem Jurídico-Penal. São Paulo: Quartier Latin, 2014, p. 87 e ss. 
central do artigo, que trata de direito processual, a teoria do bem jurídico é determinante para as suas conclusões.

Com efeito, o trabalho se fundamenta em duas das mais importantes obras jurídicas nacionais sobre a temática: a Teoria do Injusto Penal, de Juarez Tavares, e o Bem Jurídico-Penal, de Ana Elisa Liberatore Silva Bechara. Todavia, a concepção de bem jurídico apresentada não reflete exatamente aquela defendida pelos autores mencionados.

$\mathrm{O}$ artigo afirma que "a proteção de bens jurídicos deve ser adequada e eficaz a ponto de preservar o convívio sadio entre os integrantes da população", alertando, ainda, que "a inércia do Ministério Público na promoção da apuração do fato criminoso transindividual não deve passar incólume.” ${ }^{\circ}$ Extrai-se do texto uma concepção de bem jurídico notadamente fundamentadora, que trabalha com o referido conceito como forma de legitimação da incriminação, uma vez que acredita na real capacidade de o direito penal proteger os bens jurídicos subjacentes à norma penal incriminadora.

A partir desta concepção de bem jurídico, extrai-se as principais consequências do trabalho aqui analisado: a) se o direito penal protege bens jurídicos, sua intervenção deve ser efetiva e exercida por um maior número de instituições; b) no caso dos crimes com bens jurídicos transindividuais, há um déficit de legitimação para o exercício da ação penal; c) com a expansão desta legitimidade é possível uma maior intervenção penal para proteção dos bens jurídicos e, por consequência, para a efetivação dos direitos humanos.

A despeito de se tratar de um trabalho de direito processual penal, seu fundamento central reside na questão do bem jurídico, de natureza penal. Em outras palavras, o trabalho apresenta estreita coerência e profundidade a partir da visão do autor com relação à legitimidade da intervenção penal. Todavia, referida posição é passível de críticas, mormente a partir de alguns dos próprios autores citados no trabalho.

Com efeito, Juarez Tavares defende uma posição crítica e estritamente limitadora do bem jurídico, definido como "um valor que se incorpora à norma como um objeto de preferência real e constitui, portanto, o elemento primário da estrutura do tipo, ao qual se devem re-

6 SILVA, Franklyn Roger Alves. Legitimação não tradicional da ação penal, p. 386. 
ferir a ação típica e todos os seus demais componentes."” Para Tavares, o bem jurídico exerce dois papéis fundamentais: condiciona a validade da norma penal incriminadora e subordina sua eficácia à demonstração de que tenha sido lesado ou posto em perigo.

Nesse sentido, há uma diferença essencial entre fundamentar a incriminação a partir do bem jurídico e condicionar sua validade à existência de um bem jurídico. Justamente sobre esta diferença reside a primeira divergência com as premissas do texto sob crítica, segundo o qual o bem jurídico fundamenta a incriminação, e a obra utilizada como referência, na qual Juarez Tavares condiciona e, portanto, limita a incriminação à existência de um bem jurídico, ou seja, "são inválidas normas incriminadoras sem referência direta a qualquer bem jurídico".

A outra função exercida pelo bem jurídico é a necessidade de demonstração de sua efetiva lesão ou colocação em perigo como pressuposto indeclinável do próprio injusto penal, vale dizer, não se admite a incidência da normal penal incriminadora sem um resultado de dano ou de perigo ao bem jurídico.

Para Juarez Tavares, o bem jurídico na qualidade de valor "cumpre a função de proteção, não dele próprio, senão da pessoa humana, que é o objeto final de proteção da ordem jurídica”, razão pela qual o bem jurídico não deve se vincular a finalidades políticas de segurança pública, mas apenas na proteção da pessoa humana. A divergência entre a concepção adotada no texto sob crítica e Juarez Tavares, utilizado como referência, pode ser resumida na seguinte colocação do Professor Titular da UERJ: "a noção de bem jurídico não pode ser posta como legitimação da incriminação, mas como sua delimitação." ${ }^{10}$

A outra autora citada como suporte para a questão do bem jurídico, Ana Elisa Liberatore Silva Bechara, igualmente sustenta uma concepção limitadora do bem jurídico. Para ela, “a teoria do bem jurídico

7 TAVARES, Juarez. Teoria do Injusto Penal. 3. ed. Belo Horizonte: Del Rey, 2003, p. 198.

8 TAVARES, Juarez. Teoria do Injusto Penal... p. 198.

9 TAVARES, Juarez. Teoria do Injusto Penal... p. 199.

10 TAVARES, Juarez. Teoria do Injusto Penal. 3. ed. Belo Horizonte: Del Rey, 2003, p. 202. 
oferece, por si mesma, apenas critério negativo de limitação, e não de justificação da intervenção penal." ${ }^{11}$

A teoria do bem jurídico recebe na obra da autora uma função limitada, sendo apenas um dos critérios críticos na análise da legitimidade da intervenção penal. Toda a obra de Ana Elisa Liberatore Silva Bechara caminha no sentido contrário à utilização da teoria do bem jurídico como forma de fundamentação da intervenção penal, que, preocupada com os deletérios efeitos da irracional incidência do sistema penal no Brasil, alerta: "o rendimento da teoria do bem jurídico na legitimidade da intervenção penal deve ser entendido de forma bastante reduzida, não se podendo cobrar desse instituto efeitos que ele não pode eficazmente assumir." 12

Observa-se, portanto, que os autores referenciados no texto sob análise (Juarez Tavares e Ana Elisa Liberatore Silva Bechara) adotam uma concepção de bem jurídico diversa daquela presente no trabalho. Ainda que não tenham sido citados no texto, parece fundamental a referência a Nilo Batista e Eugenio Raúl Zaffaroni, que igualmente trazem uma concepção limitadora de bem jurídico, com especial crítica à ideia de bem jurídico tutelado, presente no texto em análise.

Advertem os autores que não se deve confundir o uso limitativo-redutor do conceito de bem jurídico (defendidos por Juarez Tavares e Ana Elisa Liberatore Silva Bechara) com seu uso legitimante, que acabou cunhando o conceito de "bem jurídico tutelado". Sobre o equívoco desse conceito, aduzem:

O mito de um bem jurídico protegido ou tutelado, que se racionalizou na teoria imperativista do direito, pressupõe aceitar a eficácia tutelar do poder punitivo consagrada de forma pretensamente dedutiva: se uma norma proíbe uma ação que ofende o bem jurídico, é porque o protege (e, portanto, a pena adquire um sentido policial preventivo). Trata-se de conclusão que não se logra extrair da premissa, produzindo um juízo com valor de

11 BECHARA, Ana Elisa Liberatore Silva. Teoria do Bem Jurídico-Penal. São Paulo: Quartier Latin, 2014, p. 367.

12 BECHARA, Ana Elisa Liberatore Silva. Teoria do Bem Jurídico-Penal... p. 365. 
verdade falso (as normas penais tutelam os bens jurídicos), como a operatividade real do poder punitivo demonstra. ${ }^{13}$

Para Batista e Zaffaroni, a principal função do bem jurídico é dotar de eficácia o princípio da lesividade ${ }^{14}$, de modo a restringir o poder punitivo do Estado. Em sentido diametralmente oposto, a concepção fundamentadora do bem jurídico "tutelado" leva à legitimação da expansão da intervenção penal. Esta, portanto, é a crítica central ao texto em análise: a despeito das boas intenções, alguns de seus pressupostos legitimam a expansão do poder punitivo, que no Brasil se mostra especialmente problemático.

\section{2 - A DEFENSORIA PÚBLICA E A INTERVENÇÃo PUNITIVA}

A outra questão que se impõe a partir do texto é o papel da Defensoria Pública no exercício da ação penal. Com efeito, a partir da ordem jurídica posta, é possível o exercício da ação penal pela Defensoria Pública em alguns casos expressamente previstos em lei. Todavia, a discussão nos parece superar os aspectos jurídico-formais e revela uma questão de fundo de maior importância: deve a Defensoria Pública reivindicar a ampliação do exercício da ação penal?

A resposta a esta indagação depende de um juízo de valor sobre a incidência da intervenção jurídico-penal na realidade concreta. Se o direito penal tutela bens jurídicos e com isso pode ser um instrumento efetivo para a defesa de direitos humanos, se a intervenção penal realiza suas funções declaradas de prevenção ao delito e defesa social, de fato, compreende-se que a Defensoria Pública reivindique o exercício da ação penal. A questão de fundo não é de uma mera avaliação de cunho jurídico-processual, mas de expansão ou limitação do poder punitivo do Estado e suas necessárias consequências no plano social concreto.

A defesa do exercício da ação penal pela Defensoria Pública é atualmente impulsionada pela ampliação da atuação da instituição na

13 ZAFFARONI, Eugenio Raúl; BATISTA, Nilo; ALAGIA, Alejandro; SLOKAR, Alejandro. Direito Penal Brasileiro II, i. Rio de Janeiro: Revan, 2010, p. 216.

14 ZAFFARONI, Eugenio Raúl; BATISTA, Nilo; ALAGIA, Alejandro; SLOKAR, Alejandro. Direito Penal Brasileiro II, i... p. 215. 
defesa dos direitos humanos. Nos últimos anos, a Defensoria Pública tem se notabilizado pela tutela jurídica de direitos humanos pelo exercício de ações coletivas cíveis, por meio das quais são efetivados Tratados Internacionais de Direitos Humanos que por décadas foram interpretados como meras cartas de princípios e boas intenções.

Todavia, a transposição dessa notável atuação institucional para o campo penal com o objetivo de tutela de direitos humanos parece gerar problemas trazidos tanto por uma defesa questionável de uma teoria geral do processo, que não diferencia adequadamente as consequências do exercício da ação civil e penal no plano concreto, quanto pela influência da ideologia da defesa social nos chamados mandados de criminalização previstos nos Tratados Internacionais de Direitos Humanos.

A ideia de que a intervenção penal é benéfica para a sociedade porque tutela os bens jurídicos mais importantes já foi devidamente refutada tanto no plano dogmático, cuja melhor doutrina afasta a ideia fundamentadora de bem jurídico, quanto no campo criminológico, que desvelou os reais efeitos do violento controle social punitivo.

O processo de criminalização, seja qual for o tipo de bem jurídico, individual ou coletivo, é estruturalmente seletivo, violento e estigmatizante, incidindo sobre o mesmo grupo socialmente vulnerável. Em sociedades especialmente desiguais como a brasileira, o funcionamento do sistema penal traduz-se em uma seleção de pessoas que carregam consigo características sociais, etárias, raciais, estéticas e de gênero específicas $^{15}$ que transformam o nosso processo de criminalização em uma ação de criminalização da pobreza ${ }^{16}$, com consequências verdadeiramente destrutivas da dignidade e da própria vida humana ${ }^{17}$, como demonstra nosso sistema carcerário.

15 Cf. BECHARA, Ana Elisa Liberatore Silva; CACICEDO, Patrick. Sobre la situación carcelária en Brasil. Observaciones críticas. Revista General de Derecho Penal, v. 18, 2012.

16 ZAFFARONI, Eugenio Raúl; BATISTA, Nilo; ALAGIA, Alejandro; SLOKAR, Alejandro. Direito Penal Brasileiro I. Rio de Janeiro: Revan, 2003, p. 48.

17 CACICEDO, Patrick. Pena e funcionalismo sistêmico: uma análise crítica da prevenção geral positiva. 2014. Dissertação (Mestrado em Direito) Faculdade de Direito da Universidade de São Paulo, São Paulo, p. 142. 
Nas últimas décadas, o Brasil vive um verdadeiro processo de encarceramento em massa da pobreza, cuja contribuição da política de drogas tem ocupado um papel de destaque. A defesa da legitimidade subsidiária da Defensoria Pública para o exercício da ação penal em crimes com bens jurídicos coletivos viabilizaria, por exemplo, que a instituição se torne mais uma agência repressora dessa irracional política de guerra às drogas. Inclusive, mesmo o caráter subsidiário da referida legitimidade institucional não retiraria seu papel legitimante do poder punitivo e de todas as suas consequências.

A seletividade penal revela-se também na incapacidade estrutural das agências do sistema penal operacionalizarem toda a programação da lei penal (criminalização primária), o que não significa que exista um déficit de persecução penal no Brasil, como demonstram os números do nosso crescente encarceramento em massa. Eventual inércia persecutória sempre existirá, visto que é própria da estrutura do sistema penal, mas isso não deve levar à expansão de um sistema já esgotado em suas possibilidades repressoras.

Assim, para além da questão jurídico-processual, desenvolvida com profundidade no artigo aqui em análise, trata-se de uma questão político criminal da maior relevância: a instituição constitucionalmente encarregada de garantir os direitos humanos dos vulneráveis deve participar de um processo de criminalização que necessariamente recairá sobre os destinatários do seu serviço?

A outra opção é resistir às tentações do poder punitivo e reconhecer que na seara criminal o papel da Defensoria Pública é seguir ao lado dos desvalidos do mundo e deslegitimar o poder que oprime justamente os destinatários de sua atividade. Neste sentido, o papel da Defensoria Pública na área criminal é descrito de maneira brilhante por Bruno Shimizu e Rafael Folador Strano:

É essa resistência que, embora árdua, difusa e abstrata, possibilita a inserção do Defensor Público no sistema punitivo como agente e sujeito ético, simultaneamente. Longe de fundamentar a identificação do Defensor Público com uma autoridade, em imitação ao modo como normalmente se entendem os órgãos públicos atuantes no sistema de justiça, a criminologia de matriz radical propõe ao Defensor que se veja apenas como mais um sujeito 
que, ao lado de militantes, artistas, pensadores, loucos e tantas outras pessoas, pretenda viver de forma ética, exercendo o "cuidado de si” em suas dimensões crítica e de luta. Ao transcender o enfoque meramente processual de sua atuação para se identificar como tensionador da malha de poder, o Defensor Público, assim como todos que lutam e resistem à opressão, percebe que provavelmente jamais tateará o resultado efetivo e acabado de sua resistência. Compreende que sua conduta cotidiana relaciona-se muito mais aos meios do que aos resultados imediatos. Entende, enfim, sem que isso importe em sua opção por resistir como imperativo ético, que a luta é infinita. ${ }^{18}$

\section{ConsideraçõEs finAIS}

A análise de "Legitimação não tradicional da ação penal - a tutela de bens jurídicos por outras instituições públicas" sob a ótica penal e criminológica possibilita a reflexão sobre as consequências da tese ali sustentada para além de questões jurídico-formais do direito processual penal. A breve análise realizada nesta crítica científica revela uma preocupação com os rumos da Defensoria Pública na esfera penal, que, ao se mostrar incapaz de tutelar bens jurídicos por meio do direito penal, pode se tornar mais um agente impulsionador do poder punitivo do Estado, com a consequente reprodução das desigualdades sociais e da violação da vida e dignidade humanas, justamente o reverso da ideia que motivou sua constituição como mecanismo de defesa dos direitos humanos dos vulneráveis.

\section{REFERÊNCIAS}

BECHARA, Ana Elisa Liberatore Silva. Teoria do Bem Jurídico-Penal. São Paulo: Quartier Latin, 2014.

BECHARA, Ana Elisa Liberatore Silva; CACICEDO, Patrick. Sobre la situación carcelária en Brasil. Observaciones críticas. Revista General de Derecho Penal, v. $18,2012$.

18 STRANO, Rafael Folador; SHIMIZU, Bruno. O defensor público e a criminologia: da 'desalienação' à resistência. In: RÉ, Aluísio Iunes Monti Ruggeri (Org.). Temas aprofundados da Defensoria Pública. Salvador: Juspodivm, 2013, p. 394. 
BIRNBAUM, Johann Michael Franz. Sobre la necesidad de una lesión de derechos para el concepto de delito. Traducción de José Luiz Guzmán Dalbora. Buenos Aires: B de F Editorial, 2010.

CACICEDO, Patrick. Pena e funcionalismo sistêmico: uma análise crítica da prevenção geral positiva. 2014. Dissertação (Mestrado em Direito) - Faculdade de Direito da Universidade de São Paulo, São Paulo.

SILVA, Franklyn R. A. Legitimação Não Tradicional da Ação Penal - A Tutela de Bens Jurídicos por Outras Instituições Públicas. Revista Brasileira de Direito Processual Penal, Porto Alegre, vol. 3, n. 1, p. 367-404, jan./abr. 2017. https:// doi.org/10.22197/rbdpp.v3i1.27

TAVARES, Juarez. Teoria do Injusto Penal. 3. ed. Belo Horizonte: Del Rey, 2003.

ZAFFARONI, Eugenio Raúl; BATISTA, Nilo; ALAGIA, Alejandro; SLOKAR, Alejandro. Direito Penal Brasileiro I. Rio de Janeiro: Revan, 2003.

ZAFFARONI, Eugenio Raúl; BATISTA, Nilo; ALAGIA, Alejandro; SLOKAR, Alejandro. Direito Penal Brasileiro. Vol. II, i. Rio de Janeiro: Revan, 2010.

Dados do processo editorial - crítica científica (http://www.ibraspp.com.br/revista/index.php/RBDPP/about/editorialPolicies)

- Recebido em: 12/09/2016

- Decisão preliminar e verificação de plágio: $12 / 12 / 2016$ Equipe editorial envolvida

- Retorno rodada de correções 1: 13/12/2016

- Decisão editorial final: 13/12/2016

\section{COMO CITAR ESTE TRABALHO:}

CACICEDO, Patrick. Crítica científica a "Legitimação não tradicional da ação penal": Defensoria Pública e a tutela de direitos por meio do direito penal - uma recusa. Revista Brasileira de Direito Processual Penal, Porto Alegre, vol. 3, n. 1, p. 407-416, jan./abr. 2017. https://doi.org/10.22197/rbdpp.v3i1.35 